\title{
Late-life depression: issues for the general practitioner
}

This article was published in the following Dove Press journal: International Journal of General Medicine

\author{
Axel Van Damme' \\ Tom Declercq ${ }^{2}$ \\ Lieve Lemey ${ }^{3}$ \\ Hannelore Tandt ${ }^{4}$ \\ Mirko Petrovic ${ }^{5}$ \\ 'Faculty of Medicine and Health \\ Sciences, Ghent University, Ghent, \\ Belgium; ${ }^{2}$ Department of General \\ Practice and Primary Health \\ Care, Ghent University, Ghent, \\ Belgium; ${ }^{3}$ Department of Psychiatry, \\ AZ Sint-Jan Brugge-Oostende AV, \\ Brugge, Belgium; ${ }^{4}$ Department of \\ Psychiatry, Ghent University Hospital, \\ Ghent, Belgium; ${ }^{5}$ Department \\ of Internal Medicine, Section of \\ Geriatrics, Ghent University, Ghent, \\ Belgium
}

Correspondence: Mirko Petrovic Department of Internal Medicine, Section of Geriatrics, Ghent University, Heymanslaan 10, B-9000 Ghent, Belgium Email mirko.petrovic@ugent.be

\begin{abstract}
Late-life depression (LLD) is both a prevalent and life-threatening disorder, affecting up to $13.3 \%$ of the elderly population. LLD can be difficult to identify because patients mainly consult their general practitioner (GP) for somatic complaints. Moreover, patients may be hesitant to express the problem to their GP. Increased vigilance on the part of the GP can only benefit older people with depression. To recognize the risk of LLD, screening tools are provided in addition to treatment options for LLD. This review aims to provide the GP with guidance in recognizing and treating LLD. It tries to connect mainstream etiologies of LLD (e.g., vascular, inflammation, hypothalamo-pituitary-adrenal axis) with risk factors and current therapies. Therefore, we provide a basis to the GP for decision-making when choosing an appropriate therapy for LLD.
\end{abstract}

Keywords: geriatric mental health, major depressive disorder, elder care, psychosomatic, geriatric psychiatry

\section{Introduction}

Late-life depression (LLD), with an estimated prevalence of $13.3 \%$, is a common mental health disorder in older people. ${ }^{1}$ It is associated with increased morbidity and mortality in addition to a high societal cost. ${ }^{2}$ Moreover, the treatment cost of an older person with depression is 1.86 times higher than that of an older person without depression. ${ }^{3}$ The consequences of untreated LLD include poor quality of life, exacerbation of chronic illnesses, and suicide. ${ }^{4}$ Due to the atypical presentation, the diagnosis is often missed by general practitioners (GPs), which consequently leads to undertreatment of the disease. ${ }^{5}$ However, an LLD diagnosis in time can be life-saving and, when treated, LLD has a good prognosis; up to $70 \%$ of older patients with depression treated with antidepressants recover from a depressive episode. ${ }^{6}$ The aim of this review is to provide a comprehensive and practical guide for GPs with regard to the main risk factors as well as the diagnostic and therapeutic approach to LLD.

\section{Definition of the problem}

LLD can be defined as depression that occurs for the first time after age 60 . When we use the term "depression", we refer to major depressive disorder as defined by the Diagnostic and Statistical Manual of Mental Disorders 5 (DSM-5). The cardinal symptoms of major depressive disorder are anhedonia (a loss of interest in activities one used to enjoy) and a depressed mood through most of the day. ${ }^{7}$ According to the 
DSM 5, an older person has an episode of major depression if he or she has at least one cardinal symptom and four or more of the following symptoms for at least 2 weeks: significant decrease or increase in weight or appetite; insomnia or hypersomnia, fatigue, psychomotor agitation, or retardation; diminished ability to concentrate or make decisions; feelings of worthlessness or inappropriate guilt; and recurrent thoughts of death or suicidal ideation. In the elderly, depressive feelings may often be masked by unexplained physical complaints (e.g., fatigue, diffuse pain or back pain, headache, chest pain, etc.) and, consequently, the classical DSM 5 criteria sometimes seem to fail in terms of diagnosing depression in elders. ${ }^{8}$

Furthermore, the conditions mentioned above can exist concomitantly. The differential diagnosis of LLD is broad (Table 1). Physical examination and cognitive screening may be useful in ruling out common conditions that are often confused with depression and in assessing for commonly co-occurring diseases. Consequently, a thorough medical history, Mini Mental State Exam, physical examination, and, sometimes, further technical investigations are recommended. Indications for referring patients to a geriatric psychiatrist are presented in Table $2 .{ }^{8}$

A particularly difficult differential diagnosis of LLD is dementia (see Table 3). Moreover, Parkinson disease (PD) is a prevalent neurodegenerative disease associated with depression and occurs in up to $35 \%$ of patients with PD. ${ }^{10}$ Depression associated with PD is not a single entity, but rather a heterogeneous group of three subtypes where only one group is directly related to the pathophysiology of PD. ${ }^{11}$ The signs of depression linked to PD include nonresponse to at least one course of antidepressant treatment, absence of suicidal behavior, absence of guilt and self-blame, and no personal history of depression. The pathophysiological mechanism of depression in PD is unknown, but a current hypothesis

Table I Differential diagnosis of late-life depression

Central nervous system disorders (dementia, Parkinson disease, and neoplastic lesions)

Related psychiatric disorders (dysthymia, bipolar, and anxiety disorders)

Endocrine disorders (hypothyroidism, hyperthyroidism, and

hyperparathyroidism)

Adverse events of some pharmacological agents (e.g., $\beta$-blockers, centrally active antihypertensive medications, steroids, $\mathrm{H}_{2}$-blockers, sedatives, certain chemotherapy agents)

Life circumstances (e.g., grief, bereavement, financial loss)

Substance use, abuse, or dependence

Infectious and inflammatory diseases (e.g., HIV encephalopathy, systemic lupus erythematosus) and sleep disorders (in particular, obstructive sleep apnea)

Note: Data from Fountoulakis et al. ${ }^{9}$
Table 2 Summarizing table

Patients at risk for late-life depression

- Poor physical health and frailty

- Female gender

- Oldest elders ( $\geq 80$ years)

- Cognitive impairment and neurodegenerative disease

- Nutritional deficits

- Vascular events

- Lifestyle: smoking, alcohol, multiple medications

- Being single or widow(er)

\begin{tabular}{lcl}
\hline Screening tools & & \\
\hline GDS & CES-D & PHQ2 \\
\hline - Yes/no format & - Scoring statements & - Two yes/no \\
- Takes 3-4 min to & with 0-3 scores & questions \\
complete & - Takes 5 min to & - Takes $<$ I min to \\
- Validated for the oldest & complete & complete \\
elders and MMSE >10 & - Validated in & - If positive, \\
- Preferred screening tool & patients suffering & further \\
for Parkinson disease & from dementia & investigations \\
- Cutoff 30-item list: 10-19, & - Cutoff: $\geq 20$, major & are necessary \\
mildly depressed 20-30, & depression &
\end{tabular}

severely depressed

- Cutoff I5-item list: $\geq 5$, major depressive disorder

\begin{tabular}{lcl}
\hline Treatment options based on stepped care & \\
\hline Nonpharmacological & Pharmacological & ECT \\
\hline - Psycho-education & - Substitution & Reserved for \\
- Psychotherapy & therapy (when & - Oldest elders \\
- Patients who prefer & deficit is present) & $(\geq 80$ years) \\
talking over medication & - Vitamin D: & - Treatment- \\
- As adjunctive therapy & 2,000 IU daily & refractory \\
- Structured physical & - Folic acid: & depression \\
exercise & $800 \mu g-2$ mg & - Psychotic \\
- Frequency: 3-4 times a & - Antidepressants & depression \\
week & - SSRIs (e.g., & - Depression \\
- One session: & sertraline) & with severe \\
$45-60$ min & - TCAs (e.g., & weight loss and \\
& nortriptyline) & anorexia \\
& - SNRIs (e.g., & - Psychomotor \\
& duloxetine, & agitation or \\
& venlafaxine) & retardation \\
& - Mirtazapine &
\end{tabular}

Consider referral to a mental health specialist: preference nonpharmacological treatment, persistent depression (one to three trials of antidepressants), psychosis, mania, or concern about suicide

Abbreviations: GDS, Geriatric Depression Scale; CED-D, Center for Epidemiologic Studies; PHQ2, Patient Health Questionnaire; MMSE, Mini-Mental State Examination; ECT, electroconvulsive therapy; SSRIs, selective serotonin reuptake inhibitors; TCAs, tricyclic antidepressants; SNRIs, serotonin-norepinephrine reuptake inhibitors.

implies genetic factors, Lewy body pathology, stress-induced hypercortisolemia, inflammation, psychosocial aspects, and changes in monoaminergic signaling. ${ }^{10}$

In the assessment of LLD, exclusion of somatic causes of depression through patient history, clinical examination, laboratory tests, and/or imaging is the first step in appraising LLD. ${ }^{12}$ A GP who has good knowledge of the patient's personality can identify nonverbal cues and changes in behavior suspicious for mood problems. ${ }^{13}$ In addition, information from family members and/or caregivers on the patient's mood, 
Table 3 Differential diagnosis: late-life depression versus dementia

\begin{tabular}{|c|c|c|}
\hline & Late-life depression & Dementia \\
\hline Onset & Slow or acute & Slow and progressive onset \\
\hline Evolution & Chronological order of events can be recalled & History of the disease cannot be restored by the patient \\
\hline $\begin{array}{l}\text { Quality of life (as experienced by } \\
\text { the patient) }\end{array}$ & Decreased & $\begin{array}{l}\text { The patient does not experience his/her disease as a } \\
\text { problem }\end{array}$ \\
\hline \multirow[t]{3}{*}{ Memory } & Decreased ability to think or concentrate or being & Decreased \\
\hline & slowed down & $\begin{array}{l}\text { Impaired ability to learn new information or to recall } \\
\text { previously learned information }\end{array}$ \\
\hline & & Patient tries to hide cognitive problems \\
\hline Language and praxis & Normal & Decreased \\
\hline Affect & Apathetic, depressed mood, psychomotor retardation & Lability of affect \\
\hline \multirow[t]{4}{*}{ Somatic } & Sleep disturbances & Can be present, but will not be chief complaint \\
\hline & Somatic problems (insomnia, dizziness, pain, etc.) & \\
\hline & Low energy & \\
\hline & Diurnal mood variation & \\
\hline Prognosis & Treatable & Irreversible \\
\hline
\end{tabular}

functioning and behavior is crucial for assessing the older person with depression.

There is no golden standard for bringing up depression; it is dependent on the physician's manner, and research on the topic is lacking. To engage the patient, the use of the bio-psychosocial model may be helpful: inform the patient that the illness is an interaction between physiological (e.g. serotonin hypothesis), psychological, and social factors. ${ }^{14}$

\section{Risk factors}

The risk factors for LLD are a combination of biological and psychosocial factors.

\section{Biological risk factors}

The biological risk factors associated with LLD are old age and female sex..$^{15}$ In addition, there may be a genetic vulnerability, making some people more susceptible to LLD than others. ${ }^{16}$

Patients with poor physical health (e.g. multiple comorbidities, sleeping disorders, etc.) may be predisposed to LLD. ${ }^{17}$ These people often use more medication, which in itself is a risk factor for LLD. ${ }^{18}$

The concept of frailty stresses a loss of function in several domains of functioning (not only the physical), leading to a decline in the reserve capacity for dealing with stressors. Frailty can be defined by the Fried criteria: weight loss, decreased handgrip strength, slowness, exhaustion, and low physical activity. ${ }^{19}$ Physical frailty is linked to chronic inflammation and LLD. ${ }^{20,21}$ Poor nutritional status is associated with frailty; therefore, nutritional supplements (vitamin $\mathrm{D}$ and proteins) could benefit the depressed frail patient. ${ }^{22}$ Nutritional deficits that are often reported in older people with depression are vitamin B12 and folate deficiencies. ${ }^{23}$ The current hypothesis states that vitamin D affects mood by interacting with brain receptors in the limbic structures and hippocampus. ${ }^{24}$

Neurodegenerative disease (e.g., PD or Alzheimer) and mild cognitive impairment (MCI) has also been considered a possible risk factor for LDD. ${ }^{25}$ There are hypotheses that LLD may lead to MCI and, consequently, dementia. ${ }^{25}$ The debate is still ongoing, and the current literature is inconclusive about LLD being a prodrome of dementia. ${ }^{27}$ What we do know is that LLD and dementia frequently co-occur, and depression can be the first sign of dementia. ${ }^{28,29}$

The vascular hypothesis states that cerebrovascular disease may cause or predispose to LLD. The concept of vascular depression as a clinical entity is inherently linked to this hypothesis and can be explained by reduced cerebral perfusion, altered brain connectivity due to vascular brain lesions, and chronic low-grade inflammation. ${ }^{30} \mathrm{LLD}$ has been linked to atherosclerosis, which is - at the same time - the leading cause of coronary heart disease. ${ }^{31}$

\section{Psychosocial risk factors}

Kaji et al point out that psychological factors such as loss of purpose in life or human relationships seem to be associated with LLD. ${ }^{32}$ Moreover, lower education has been linked to LLD. ${ }^{33}$ Being a widower or single is a risk factor for LLD, but possibly reflects the fact that loneliness, lack of social support, and stressful life events or poverty are the risk factors for depression in old age. ${ }^{34}$ Being functional or visually impaired increases the risk of developing LLD. ${ }^{35}$

Poor lifestyle habits can put elders at risk for LLD. Both smoking and alcohol use are the risk factors of LLD. ${ }^{18}$ In 
addition, the use of sleep medication has been linked to LLD, but sleep disturbance in general is a risk factor for LLD. ${ }^{35}$

\section{Screening}

In the following text, we only discuss screening tools validated in a geriatric and primary care setting. These tools should not be used systematically; rather, an opportunistic screening is advised in patients in whom LLD is suspected. In Table 4, we compare the Geriatric Depression Scale (GDS), Center for Epidemiologic Studies Depression Scale (CES-D), and Patient Health Questionnaire 2 (PHQ-2).

\section{Approach}

The recommended approach to LLD is stepped care: treatment is based on the severity of depression and preference of the. ${ }^{42}$ The severity of the depressive disorder (mild, moderate, or severe) is based on the number of symptom criteria, the severity of those symptoms, and their functional disability in the DSM-5. If the selected treatment for LLD is inadequate, the GP should step up and provide the next step of treatment (see Figure 1). A summary of risk factors, screening tools, and interventions are provided in Table 2.

\section{Prevention}

The risk factors that can be modified are nutritional deficiencies and cardiovascular disease, which are more common at

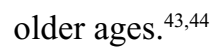

Vascular risk factors can be improved by exercise, diet, smoking cessation as well as treatment for hypertension, hypercholesterolemia, and hyperglycemia. ${ }^{45,46}$ These inter-

Table 4 Comparison of validated screening tools for late-life depression in primary care

\begin{tabular}{|c|c|c|c|}
\hline & Geriatric Depression Scale (GDS)- I $5^{36}$ & $\begin{array}{l}\text { Center for Epidemiologic Studies } \\
\text { Depression Scale (CES-D) }\end{array}$ & $\begin{array}{l}\text { Patient Health } \\
\text { Questionnaire } 2 \text { (PHQ-2) }{ }^{38}\end{array}$ \\
\hline What & Yes/no questionnaire & $\begin{array}{l}\text { A short self-report scale of } 20 \text { statements, divided } \\
\text { into multiple categories, designed to measure } \\
\text { depressive symptoms over the past week }\end{array}$ & $\begin{array}{l}\text { Questions depressed mood } \\
\text { and anhedonia in the previous } \\
2 \text { weeks }\end{array}$ \\
\hline Cutoff & 5 & 25 & $\begin{array}{l}\text { Positive response to one of the } \\
\text { two questions }\end{array}$ \\
\hline Sensitivity & $79 \%-100 \%{ }^{37}$ & $85 \%{ }^{39}$ & $100 \%{ }^{4}$ \\
\hline Specificity & $67 \%-80 \%^{37}$ & $64 \%^{39}$ & $77 \%^{4}$ \\
\hline Time to complete & $3-4 \min$ & $5 \mathrm{~min}$ & $\mathrm{I} \min$ \\
\hline Extra & $\begin{array}{l}\text { I. Validated in the oldest elder ( } \geq 80 \text { years) } \\
\text { with cognitive impairment (lower limit: } \\
\text { Mini-Mental Status Exam } 10)^{40} \\
\text { 2. Preferred screening instrument in } \\
\text { Parkinson patients }\end{array}$ & $\begin{array}{l}\text { Can be used for patients with patients with } \\
\text { dementia (average Mini-Mental Status Exam score } \\
\text { of } 19)^{41}\end{array}$ & \\
\hline
\end{tabular}

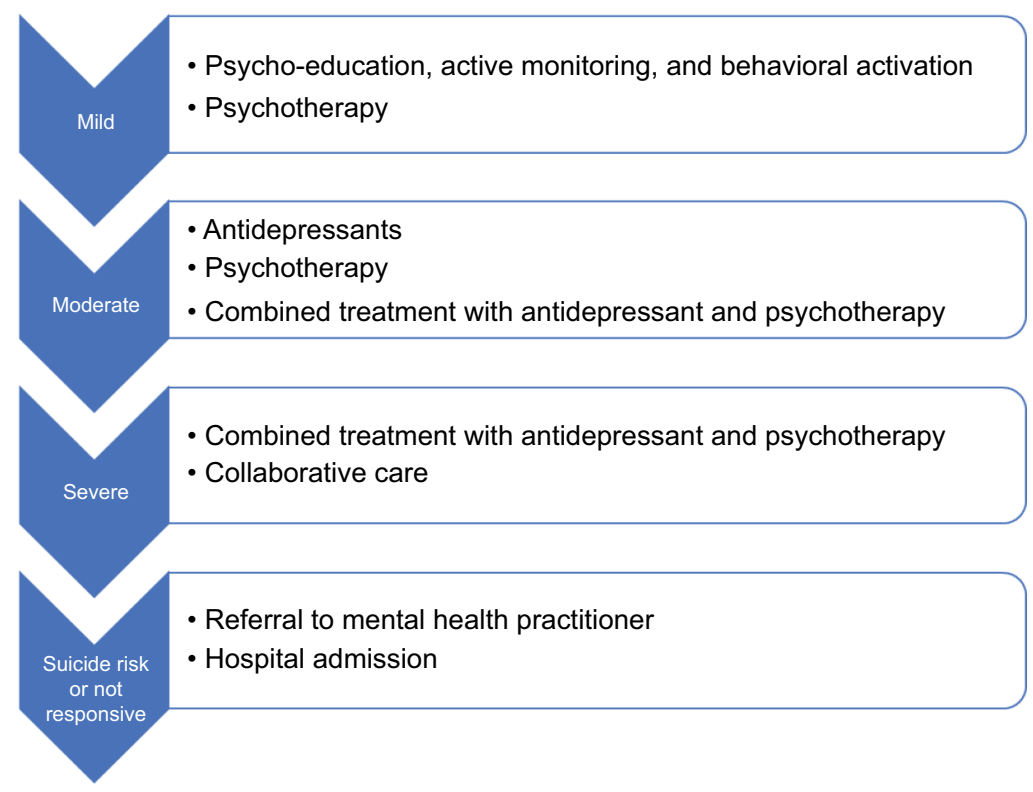

Figure I Stepped care approach to late-life depression, based on the severity of depression and patient preference. Initiate the next step if the patient does not respond to the therapy. 
ventions reduce the further progression of atherosclerosis and prevent diabetes and cerebrovascular disorders - all of which are linked to LLD. ${ }^{45,47}$

Nutritional supplementation, such as a high dose of vita$\min \mathrm{D}(2,000 \mathrm{IU}$ daily), folic acid ( $800 \mu \mathrm{g}-2 \mathrm{mg})$, and a highprotein diet (for frail elders), for a deficiency of vitamins or folic acid in older people (including the frail) with depression has been suggested to alleviate depressive symptoms..$^{22,24,48}$

\section{Nonpharmacological treatment Psycho-education}

The GP plays a central role in providing psycho-education: to clarify major depressive disorder, to explain therapeutic options, discuss biopsychological vulnerability, to teach to recognize warning signs, and to inform and support the spouse. ${ }^{49}$ In addition, the primary physician actively monitors the patient through frequent visits. Moreover, the primary physician tries to provide a structure in the patient's life and activate the patient through structured and fun activities. ${ }^{50}$ The structure provided must be manageable for the patient and should lead to positive feelings. A balance between tasks and relaxation is essential. Healthy food, sufficient sleep, and daily interactions are a prerequisite.

\section{Behavioral activation}

Structured physical activity is recommended for older people with mild or moderate depression who are physically capable and can be motivated to exercise. ${ }^{51}$ Exercise is safe and effective in addition to the pharmacological treatment of depression. ${ }^{51}$ Mere referral of an older person with depression is not enough. ${ }^{52}$ Primary care physicians and psychiatrists should take an active role in keeping the patient motivated and managing the exercise-related adverse effects. ${ }^{53} \mathrm{~A}$ recent meta-analysis recommends structured, supervised exercise programs, three times a week (45-60 min), over 10-14 weeks, and at low intensity for mild to moderate depression. ${ }^{51}$

\section{Psychotherapy}

Psychotherapy is the most important type of nonpharmacological treatment. In LLD, psychotherapy decreases depressive symptoms in older people with depression. ${ }^{54}$ Psychotherapeutic interventions can prevent LLD in older people with sub-syndromal depression ${ }^{55}$ and are not inferior to pharmacological treatment. ${ }^{56}$ Evidence-based psychotherapeutic treatments of depression in older adults include cognitive behavioral therapy (CBT), problem-solving therapy (PST), reminiscence therapy, and interpersonal therapy (IPT). ${ }^{57}$ One relatively new therapy is life review therapy, where the patient shares and talks about important life events and memories with their therapist. A randomized controlled trial (RCT) proved that life review therapy is effective in depressed older adults and also reduces anxiety. ${ }^{58}$ In addition, life review therapy has already been implemented with success in a structured multidisciplinary approach in nursing homes and led to reduced prevalence of depression. ${ }^{50}$

\section{Pharmacological treatment}

Older adults have different pharmacodynamics and pharmacokinetics due to age-related physiological changes. ${ }^{59}$ Medication must be administered at lower doses or slowly titrated while actively monitoring the patient. ${ }^{60}$ Patients with comorbidities usually take multiple drugs. Increased vigilance for drugs interactions is, therefore, necessary. ${ }^{61} \mathrm{~A}$ careful review of the patient's drug history is recommended. Moreover, when choosing a psychotropic drug, one needs to keep track of the drug's safety profile. Because falls can invalidate old adults and even lead to increased mortality (hip fracture), avoid medications that sedate the patient. ${ }^{62,63}$

In primary care, both tricyclic antidepressants (TCAs) and selective serotonin reuptake inhibitors (SSRIs) are the pharmacological treatments of choice. ${ }^{64}$ Existing evidence suggests that no one class of antidepressant drugs has been found to be more effective than another in the treatment of LLD. ${ }^{65}$ Although newer antidepressants are not more effective than older ones, they are better tolerated and are safer, especially in cases of overdose. ${ }^{60}$ The adverse effect data suggest the modest superiority of SSRIs over TCAs. ${ }^{66}$ When choosing an SSRI, slight preference goes to an SSRI with the least known drug interactions such as sertraline or (es) citalopram. Citalopram has a Food and Drug Administration (FDA) black-box warning for increased risk of arrhythmia (QTc prolongation), which is why sertraline is preferred over citalopram. ${ }^{67}$ TCAs are as effective as SSRIs for LLD, but are less often used because of frequent side effects. ${ }^{68}$ TCAs with lesser anticholinergic side effects, such as nortriptyline, are recommended by the authors. Both SSRIs and TCAs are associated with fracture risk, although causality is not proven. ${ }^{69}$

Serotonin and noradrenaline reuptake inhibitors (SNRIs; e.g., duloxetine, venlafaxine) are an alternative to SSRIs for depressed older adults when SSRIs are ineffective or contraindicated..$^{70,71}$ SNRIs are not only effective against the major depressive disorder but also effective in the treatment of peripheral neuropathic pain.

Another second-generation antidepressant that can be used as an alternative for SSRIs is mirtazapine. The sedative side effects of mirtazapine are used as a treatment for 
insomnia. ${ }^{72}$ In addition, mirtazapine improves the appetite and can be used for anorexia. ${ }^{73}$ The effect of mirtazapine on sodium levels is limited, and therefore, less hyponatremia is noted in patients taking mirtazapine. ${ }^{74}$

Important and frequent side effects and contraindications of antidepressants are reported in Table 5.

\section{Electroconvulsive therapy}

An effective treatment for LLD, available from mental health specialists, is electroconvulsive therapy (ECT). In ECT, an electrical stimulus is given for a brief period to produce a generalized seizure. Multiple RCTs have proved that ECT is beneficial for LLD, especially psychotic depression, treatment-refractory depression, catatonia, and depression with severe weight loss and anorexia. ${ }^{75,77}$ ECT is an effective and safe treatment for depression in adults, including the oldest elders ( $\geq 80$ years). ${ }^{77}$ Recent evidence suggests old age is a positive predictor of response to ECT: it gives faster and higher remission rates as compared to antidepressants. ${ }^{78}$ A meta-analysis of the cognitive effects of ECT

Table 5 Side effects and relative contraindications of antidepressant treatment

\begin{tabular}{|c|c|c|}
\hline & $\begin{array}{l}\text { Important and frequent side } \\
\text { effects }\end{array}$ & $\begin{array}{l}\text { Relative } \\
\text { contraindications }\end{array}$ \\
\hline SSRIs & $\begin{array}{l}\text { - Gastrointestinal irritation, } \\
\text { - Pausea, or diarrhea } \\
\text { - Increased risk of gastrointestinal } \\
\text { bleeding (due to direct effect of } \\
\text { serotonin on platelets) } \\
\text { - Hyponatremia (due to } \\
\text { syndrome of inappropriate } \\
\text { antidiuretic hormone secretion) } \\
\text { - Falls and fractures } \\
\text { - Serotonin syndrome }\end{array}$ & $\begin{array}{l}\text { - Bipolar disorder } \\
\text { - Hypersensitivity } \\
\text { - Concomitant use } \\
\text { of monoamine } \\
\text { oxidase inhibitors }\end{array}$ \\
\hline TCAs & $\begin{array}{l}\text { - Anticholinergic symptoms } \\
\text { (constipation, dry mouth, } \\
\text { blurred vision, and retention of } \\
\text { urine) } \\
\text { - Arrhythmia } \\
\text { - Orthostatic hypotension } \\
\text { - Falls and fractures }\end{array}$ & $\begin{array}{l}\text { - Recent } \\
\text { myocardial } \\
\text { infarction } \\
\text { - Heart failure } \\
\text { - Arrhythmias } \\
\text { - Glaucoma }\end{array}$ \\
\hline SNRIs & $\begin{array}{l}\text { - Gastrointestinal irritation } \\
\text { - Sexual side effects } \\
\text { - Headaches } \\
\text { - Excessive sweating } \\
\text { - Hypertension }\end{array}$ & $\begin{array}{l}\text { - Disturbed liver } \\
\text { function } \\
\text { - Renal clearance } \\
<30 \mathrm{~mL} / \mathrm{min} \\
\text { - Uncontrollable } \\
\text { hypertension }\end{array}$ \\
\hline Mirtazapine & $\begin{array}{l}\text { - Sedation } \\
\text { - Increased appetite and weight } \\
\text { - Dry mouth }\end{array}$ & $\begin{array}{l}\text { - Use of } \\
\text { monoamine } \\
\text { oxidase inhibitors } \\
\text { - Hypersensitivity }\end{array}$ \\
\hline
\end{tabular}

Abbreviations: SSRIs, selective serotonin reuptake inhibitors; TCAs, tricyclic antidepressants; SNRIs, serotonin-norepinephrine reuptake inhibitors. suggests its relative safety and the transient character of its effects on memory. ${ }^{79}$ Autobiographical memory is affected by ECT, but restored or improved 6 months after treatment. ${ }^{80}$ Compared to antidepressants, ECT induces a higher speed of remission. ${ }^{81}$

\section{Multidisciplinary approach}

A multidisciplinary approach to LLD can be achieved through a collaborative care model. Collaborative care was designed in the United States for patients with (chronic) depression, wherein the GP who cares for a depressed elder is supported by a care manager and a multidisciplinary team comprising a psychiatrist and nurses. In this model, there is a shared responsibility of the depressed patient and the patient can benefit from different albeit synergistic approaches of LLD. Collaborative care is more effective than the standard care by GPs and was successfully tested in the United States, England, and the Netherlands. ${ }^{82-85}$ In general practice, the patient and his close family members can be invited once or twice a year to a "home meeting". Those present at these meetings are the most relevant caregivers: the physiotherapist, the social worker, the home nurse, the occupational therapist, and the GP. In this meeting, the patient can express hislher needs, whereas the other members can balance what's going well with what can improve the treatment of the patient. These recommendations then guide the treatment plan. If deemed necessary, the patient can be extensively investigated in a geriatric day-care hospital. In a few cases of severe and recurrent depression, a case manager (e.g., working in a geriatric psychiatric clinic) can be asked to coordinate the implementation of the defined treatment plan.

\section{Conclusion}

LLD is a prevalent disease that often presents with atypical symptoms and more somatic (co)morbidities and complaints. A stepped care model to treat depression is advised, taking into account the severity of the depression. Due to the somatic co(morbidities), a collaborative care model is preferred. The collaborative care model has proven efficacy and costeffectiveness in LLD.

\section{Disclosure}

The authors report no conflicts of interest in this work.

\section{References}

1. Beekman AT, Copeland JR, Prince MJ. Review of community prevalence of depression in later life. Br J Psychiatry. 1999;174(4):307-311.

2. Blazer DG. Depression in late life: review and commentary. J Gerontol A Biol Sci Med Sci. 2003;58(3):M249-M265. 
3. Bock JO, Brettschneider C, Weyerer S, et al. Excess health care costs of late-life depression - results of the AgeMooDe study. J Affect Disord. 2016;199:139-147.

4. Unützer J. Clinical practice. Late-life depression. $N$ Engl J Med. 2007;357(22):2269-2276.

5. Mitchell AJ, Rao S, Vaze A. Do primary care physicians have particular difficulty identifying late-life depression? A meta-analysis stratified by age. Psychother Psychosom. 2010;79(5):285-294.

6. Bottino CM, Barcelos-Ferreira R, Ribeiz SR. Treatment of depression in older adults. Curr Psychiatry Rep. 2012;14(4):289-297.

7. American Psychiatric Association. Diagnostic and Statistical Manual of Mental Disorders (DSM-5®). American Psychiatric Publishing; Washington, DC:2013.

8. Greenstein SP, McGonigle D, Kellner CH. Late-life depression. In: Simon AB, New AS, Goodman WK, editors. Mount Sinai Expert Guides: Psychiatry. Chichester, West Sussex: John Wiley \& Sons, Ltd; 2017:312-321.

9. Fountoulakis KN, O’Hara R, Iacovides A, et al. Unipolar late-onset depression: a comprehensive review. Ann Gen Hosp Psychiatry. 2003;2(1):11.

10. Aarsland D, Påhlhagen S, Ballard CG, Ehrt U, Svenningsson P. Depression in Parkinson disease - epidemiology, mechanisms and management. Nat Rev Neurol. 2012;8(1):35-47.

11. Even C, Weintraub D. Is depression in Parkinson's disease (PD) a specific entity? J Affect Disord. 2012;139(2):103-112.

12. Glover J, Srinivasan S. Assessment of the person with late-life depression. Psychiatr Clin North Am. 2013;36(4):545-560.

13. Wittink MN, Barg FK, Gallo JJ. Unwritten rules of talking to doctors about depression: integrating qualitative and quantitative methods. Ann Fam Med. 2006;4(4):302-309.

14. Miles E. Biopsychosocial model. In: Gellman MD, Turner JR, editors. Encyclopedia of Behavioral Medicine. New York, NY: Springer; 2013:227-228

15. Sözeri-Varma G. Depression in the elderly: clinical features and risk factors. Aging Dis. 2014;3(6):465-471.

16. Tsang RS, Mather KA, Sachdev PS, Reppermund S. Systematic review and meta-analysis of genetic studies of late-life depression. Neurosci Biobehav Rev. 2017;75:129-139.

17. Aziz R, Steffens DC. What are the causes of late-life depression? Psychiatr Clin North Am. 2013;36(4):497-516.

18. Weyerer S, Eifflaender-Gorfer S, Köhler L, et al; German AgeCoDe Study group (German Study on Ageing, Cognition and Dementia in Primary Care Patients). Prevalence and risk factors for depression in non-demented primary care attenders aged 75 years and older. $J$ Affect Dis. 2008;111(2-3):153-163.

19. Fried LP, Tangen CM, Walston J, et al. Frailty in older adults: evidence for a phenotype. J Gerontol A Biol Sci Med Sci. 2001;56(3):M146-M156.

20. Soysal P, Stubbs B, Lucato P, et al. Inflammation and frailty in the elderly: a systematic review and meta-analysis. Ageing Res Rev. 2016;31:1-8.

21. Arts MH, Collard RM, Comijs HC, et al. Relationship between physical frailty and low-grade inflammation in late-life depression. J Am Geriatr Soc. 2015;63(8):1652-1657.

22. Artaza-Artabe I, Sáez-López P, Sánchez-Hernández N, FernándezGutierrez N, Malafarina V. The relationship between nutrition and frailty: effects of protein intake, nutritional supplementation, vitamin D and exercise on muscle metabolism in the elderly. A systematic review. Maturitas. 2016;93:89-99.

23. Coppen A, Bolander-Gouaille C. Treatment of depression: time to consider folic acid and vitamin B12. J Psychopharmacol. 2005;19(1):59-65.

24. Okereke OI, Singh A. The role of vitamin D in the prevention of late-life depression. J Affect Dis. 2016;198:1-14

25. Cole MG, Dendukuri N. Risk factors for depression among elderly community subjects: a systematic review and meta-analysis. $\mathrm{Am} \mathrm{J}$ Psychiatry. 2003;160(6):1147-1156.

26. Richard E, Reitz C, Honig LH, et al. Late-life depression, mild cognitive impairment, and dementia. JAMA Neurol. 2013;70(3):383-389.

27. Steffens DC. Late-life depression and the prodromes of dementia. JAMA Psychiatry. 2017;74(7):673-674.
28. Almeida OP, Hankey GJ, Yeap BB, Golledge J, Flicker L. Depression as a modifiable factor to decrease the risk of dementia. Transl Psychiatry. 2017;7(5):e1117.

29. Korczyn AD, Halperin I. Depression and dementia. J Neurol Sci. 2009;283(1):139-142.

30. Taylor WD, Aizenstein HJ, Alexopoulos GS. The vascular depression hypothesis: mechanisms linking vascular disease with depression. $\mathrm{Mol}$ Psychiatry. 2013;18(9):963-974.

31. Tiemeier H, van Dijck W, Hofman A, Witteman JC, Stijnen T, Breteler MM. Relationship between atherosclerosis and late-life depression: the Rotterdam Study. Arch Gen Psychiatry. 2004;61(4):369-376.

32. Kaji T, Mishima K, Kitamura S, et al. Relationship between late-life depression and life stressors: large-scale cross-sectional study of a representative sample of the Japanese general population. Psychiatry Clin Neurosci. 2010;64(4):426-434.

33. Chang-Quan H, Zheng-Rong W, Yong-Hong L, Yi-Zhou X, Qing-Xiu L. Education and risk for late life depression: a meta-analysis of published literature. Int J Psychiatry Med. 2010;40(1):109-124.

34. Prince MJ, Harwood RH, Blizard RA, Thomas A, Mann AH. Social support deficits, loneliness and life events as risk factors for depression in old age. The Gospel Oak Project VI. Psychol Med. 1997;27(2):323-332.

35. Djernes JK. Prevalence and predictors of depression in populations of elderly: a review. Acta Psychiatr Scand. 2006;113(5):372-387.

36. Mitchell AJ, Bird V, Rizzo M, Meader N. Diagnostic validity and added value of the Geriatric Depression Scale for depression in primary care: a meta-analysis of GDS 30 and GDS 15. JAffect Disord. 2010;125(1):10-17.

37. Watson LC, Pignone MP. Screening accuracy for late-life depression in primary care: a systematic review. J Fam Pract. 2003;52(12):956-964.

38. Manea L, Gilbody S, Hewitt C, et al. Identifying depression with the PHQ-2: a diagnostic meta-analysis. J Affect Disord. 2016;203:382-395.

39. Haringsma R, Engels G, Beekman A, Spinhoven P. The criterion validity of the Center for Epidemiological Studies Depression Scale (CES-D) in a sample of self-referred elders with depressive symptomatology. Int J Geriatr Psychiatry. 2004;19(6):558-563.

40. Conradsson M, Rosendahl E, Littbrand H, Gustafson Y, Olofsson B, Lövheim H. Usefulness of the Geriatric Depression Scale 15-item version among very old people with and without cognitive impairment. Aging Ment Health. 2013;17(5):638-645.

41. Papassotiropoulos A, Heun R, Maier W. The impact of dementia on the detection of depression in elderly subjects from the general population. Psychol Med. 1999;29(01):113-120.

42. National Collaborating Centre for Mental H. National Institute for Health and Clinical Excellence: Guidance. Depression: The Treatment and Management of Depression in Adults (Updated Edition). Leicester (UK): British Psychological Society 2010.

43. Lerner DJ, Kannel WB. Patterns of coronary heart disease morbidity and mortality in the sexes: a 26-year follow-up of the Framingham population. Am Heart J. 1986;111(2):383-390.

44. Brownie $\mathrm{S}$. Why are elderly individuals at risk of nutritional deficiency? Int J Nurs Pract. 2006;12(2):110-118.

45. Kales HC, Maixner DF, Mellow AM. Cerebrovascular disease and latelife depression. Am J Geriatr Psychiatry. 2005;13(2):88-98.

46. Iosifescu DV, Clementi-Craven N, Fraguas R, et al. Cardiovascular risk factors may moderate pharmacological treatment effects in major depressive disorder. Psychosom Med. 2005;67(5):703-706.

47. Perk J, De Backer G, Gohlke H, et al. European guidelines on cardiovascular disease prevention in clinical practice (version 2012). Eur Heart J. 2012;33(13):1635-1701.

48. Lazarou C, Kapsou M. The role of folic acid in prevention and treatment of depression: an overview of existing evidence and implications for practice. Complement Ther Clin Pract. 2010;16(3):161-166.

49. Declercq T, Habraken H, van den Ameele H. Depressie bij volwassenen: Domus Medicarichtlijn. Huisarts Nu. 2017;46:13-15.

50. Leontjevas R, Gerritsen DL, Smalbrugge M, Teerenstra S, Vernooij-Dassen MJ, Koopmans RT. A structural multidisciplinary approach to depression management in nursing-home residents: a multicentre, stepped-wedge cluster-randomised trial. Lancet. 2013;381(9885):2255-2264. 
51. Catalan-Matamoros D, Gomez-Conesa A, Stubbs B, Vancampfort D. Exercise improves depressive symptoms in older adults: an umbrella review of systematic reviews and meta-analyses. Psychiatry Res. 2016;244:202-209.

52. Orrow G, Kinmonth AL, Sanderson S, Sutton S. Effectiveness of physical activity promotion based in primary care: systematic review and meta-analysis of randomised controlled trials. BMJ. 2012;344:e1389.

53. Zanetidou S, Belvederi Murri M, Menchetti M, et al; Safety Efficacy of Exercise for Depression in Seniors Study Group. Physical exercise for late-life depression: customizing an intervention for primary care. J Am Geriatr Soc. 2017;65(2):348-355.

54. Huang AX, Delucchi K, Dunn LB, Nelson JC. A systematic review and meta-analysis of psychotherapy for late-life depression. Am J Geriatr Psychiatry. 2015;23(3):261-273.

55. Smit F, Ederveen A, Cuijpers P, Deeg D, Beekman A. Opportunities for cost-effective prevention of late-life depression: an epidemiological approach. Arch Gen Psychiatry. 2006;63(3):290-296.

56. Cuijpers P, van Straten A, Smit F. Psychological treatment of late-life depression: a meta-analysis of randomized controlled trials. Int J Geriatr Psychiatry. 2006;21(12):1139-1149.

57. Gould RL, Coulson MC, Howard RJ. Cognitive behavioral therapy for depression in older people: a meta-analysis and meta-regression of randomized controlled trials. J Am Geriatr Soc. 2012;60(10):1817-1830.

58. Korte J, Bohlmeijer ET, Cappeliez P, Smit F, Westerhof GJ. Life review therapy for older adults with moderate depressive symptomatology: a pragmatic randomized controlled trial. Psychol Med. 2012;42(6):1163-1173.

59. Allan CL, Ebmeier KP. Review of treatment for late-life depression. Adv Psychiatr Treat. 2013;19(4):302-309.

60. Nelson JC, Delucchi K, Schneider LS. Efficacy of second generation antidepressants in late-life depression: a meta-analysis of the evidence. Am J Geriatr Psychiatry. 2008;16(7):558-567.

61. Mark TL, Joish VN, Hay JW, Sheehan DV, Johnston SS, Cao Z. Antidepressant use in geriatric populations: the burden of side effects and interactions and their impact on adherence and costs. Am J Geriatr Psychiatry. 2011;19(3):211-221.

62. Kerse N, Flicker L, Pfaff JJ, et al. Falls, depression and antidepressants in later life: a large primary care appraisal. PLoS One. 2008;3(6):e2423.

63. Lam Y. Antidepressant use and recurrent falls in the elderly. Brown Univ Psychopharmacol Update. 2016;27(8):2-3.

64. Alexopoulos GS, Katz IR, Reynolds CF, 3rd, Carpenter D, Docherty JP. The expert consensus guideline series. Pharmacotherapy of depressive disorders in older patients. Postgraduate medicine. 2001; Spec No Pharmacotherapy:1-86.

65. Kok RM, Nolen WA, Heeren TJ. Efficacy of treatment in older depressed patients: a systematic review and meta-analysis of doubleblind randomized controlled trials with antidepressants. JAffect Disord. 2012;141(2-3):103-115.

66. Rief W, Nestoriuc Y, von Lilienfeld-Toal A, et al. Differences in adverse effect reporting in placebo groups in SSRI and tricyclic antidepressant trials: a systematic review and meta-analysis. Drug Saf. 2009;32(11):1041-1056.

67. Beach SR, Kostis WJ, Celano CM, et al. Meta-analysis of selective serotonin reuptake inhibitor-associated QTc prolongation. J Clin Psychiatry. 2014;75(5):e441-e449.
68. Rajji TK, Mulsant BH, Lotrich FE, Lokker C, Reynolds CF 3rd. Use of antidepressants in late-life depression. Drugs Aging. 2008;25(10):841-853.

69. Gebara MA, Lipsey KL, Karp JF, Nash MC, Iaboni A, Lenze EJ. Cause or effect? Selective serotonin reuptake inhibitors and falls in older adults: a systematic review. Am J Geriatr Psychiatry. 2015;23(10):1016-1028.

70. Alexopoulos GS. Pharmacotherapy for late-life depression. J Clin Psychiatry. 2011;72(1):e04.

71. Taylor WD. Depression in the elderly. $N$ Engl J Med. 2014;371(13): 1228-1236.

72. Ancoli-Israel S, Ayalon L. Diagnosis and treatment of sleep disorders in older adults. Am J Geriatr Psychiatry. 2006;14(2):95-103.

73. Fox CB, Treadway AK, Blaszczyk AT, Sleeper RB. Megestrol acetate and mirtazapine for the treatment of unplanned weight loss in the elderly. Pharmacotherapy. 2009;29(4):383-397.

74. Jung Y, Jun T, Kim K, Bahk W. Hyponatremia associated with selective serotonin reuptake inhibitors, mirtazapine, and venlafaxine in Korean patients with major depressive disorder. Int $J$ Clin Pharmacol Ther. 2011;49(7):437-443.

75. van der Wurff FB, Stek ML, Hoogendijk WJ, Beekman AT. The efficacy and safety of ECT in depressed older adults: a literature review. Int $J$ Geriatr Psychiatry. 2003;18(10):894-904.

76. Dombrovski AY, Mulsant BH. The evidence for electroconvulsive therapy (ECT) in the treatment of severe late-life depression. ECT: the preferred treatment for severe depression in late life. Int Psychogeriatr. 2007;19(1):10-14, 27-35; discussion 24-6.

77. Kellner C, Roy-Byrne PP, Solomon D. Unipolar major depression in adults: indications for and efficacy of electroconvulsive therapy (ECT). 2015. Available from: https://www.uptodate.com/contents/ unipolar-major-depression-in-adults-indications-for-and-efficacy-ofelectroconvulsive-therapy-ect. Accessed March 05, 2018.

78. Geduldig ET, Kellner CH. Electroconvulsive therapy in the elderly: new findings in geriatric depression. Curr Psychiatry Rep. 2016;18(4):1-6.

79. Kumar S, Mulsant BH, Liu AY, Blumberger DM, Daskalakis ZJ, Rajji TK. Systematic review of cognitive effects of electroconvulsive therapy in late-life depression. Am J Geriatr Psychiatry. 2016;24(7):547-565.

80. Verwijk E, Comijs HC, Kok RM, Spaans HP, Stek ML, Scherder EJ. Neurocognitive effects after brief pulse and ultrabrief pulse unilateral electroconvulsive therapy for major depression: a review. JAffect Disord. 2012;140(3):233-243.

81. Spaans HP, Sienaert P, Bouckaert F, et al. Speed of remission in elderly patients with depression: electroconvulsive therapy v. medication. $\mathrm{BrJ}$ Psychiatry. 2015;206(1):67-71.

82. van der Feltz-Cornelis CM. Towards integrated primary health care for depressive disorder in the Netherlands. The depression initiative. Int $J$ Integr Care. 2009;9(2): 83.

83. Richards DA, Hill JJ, Gask L, et al. Clinical effectiveness of collaborative care for depression in UK primary care (CADET): cluster randomised controlled trial. BMJ. 2013;347:f4913.

84. Thota AB, Sipe TA, Byard GJ, et al; Community Preventive Services Task Force. Collaborative care to improve the management of depressive disorders: a community guide systematic review and meta-analysis. Am J Prev Med. 2012;42(5):525-538.

85. Unützer J, Katon WJ, Fan MY, et al. Long-term cost effects of collaborative care for late-life depression. Am J Manag Care. 2008;14(2):95-100.
International Journal of General Medicine

\section{Publish your work in this journal}

The International Journal of General Medicine is an international, peer-reviewed open-access journal that focuses on general and internal medicine, pathogenesis, epidemiology, diagnosis, monitoring and treatment protocols. The journal is characterized by the rapid reporting of reviews, original research and clinical studies across all disease areas.

\section{Dovepress}

The manuscript management system is completely online and includes a very quick and fair peer-review system, which is all easy to use. Visit http://www.dovepress.com/testimonials.php to read real quotes from published authors. 